\title{
Identification of volatiles generated by potato tubers (Solanum tuberosum CV: Maris Piper) infected by Erwinia carotovora, Bacillus polymyxa and Arthrobacter sp.
}

\author{
B. P. J. de Lacy Costello, P. Evans, R. J. Ewen, H. E. Gunson, N. M. Ratcliffe* and \\ P. T. N. Spencer-Phillips \\ Faculty of Applied Sciences, University of the West of England, Frenchay Campus, Coldharbour Lane, Bristol BS16 1QY, UK
}

\begin{abstract}
Bacteria were isolated from internal tissues of surface sterilized healthy tubers of Solanum tuberosum cv. Maris Piper (8 different isolates) and from tubers inoculated with Erwinia carotovora ssp. carotovora showing soft-rot symptoms (3 different isolates), and identified by fatty acid profiling. Bacillus polymyxa and an Arthrobacter sp. were isolated from both sources, E. carotovora only from the soft-rotted tubers. The volatile organic compounds (VOCs) generated by tubers inoculated with E. carotovora, B. polymyxa and the Arthrobacter sp. were identified. Inoculated tubers of cv. Maris Piper were incubated under controlled humidity $\left(95 \%\right.$ relative humidity) and temperature $\left(10^{\circ} \mathrm{C}\right)$ to simulate typical storage conditions. B. polymyxa and Arthrobacter sp. did not cause symptoms, whilst E. carotovora caused limited soft-rot infections after 4 weeks at the low temperatures typically associated with potatoes in storage. The VOCs released to the headspace around these tubers were collected using an adsorbent system and analysed by Gas Chromatography-Mass Spectrometry (GC-MS). Twenty-two volatiles unique to E. carotovora infection of potato tubers were found, including 10 alkanes, four alkenes, two aldehydes, one sulphide, one ketone, one alcohol, one aromatic, one acid and one heterocyclic compound. B. polymyxa generated three unique volatiles: $N, N$ dimethylformamide, 1-pentadecene and 1-hexadecane. Only one volatile, 2,3-dihydrofuran, was unique to the Arthrobacter infection. Production of volatile nitrogen species from E. carotovora-infected tubers increased with time, whereas none were detected in the headspace above uninfected tubers. Further analysis using a modified GC-MS method established that ammonia, trimethylamine and several volatile sulphides were evolved from tubers infected by E. carotovora. No specific volatile was useful as a marker associated with any of the three bacterial species but in the case of E. carotovora-infected potato tubers a significant increase in the volume of compounds evolved was clearly observed. The results are discussed in relation to the use of sensors to detect VOCs evolved from infected tubers in order to provide an early warning system for the control of soft rot in potato stores.
\end{abstract}

Keywords: Erwinia, gas chromatography-mass spectrometry, potato tubers, soft rot, volatiles.

\section{Introduction}

The rotting of potato tubers in stores is a major problem for the potato industry. Bacterial soft rot (Erwinia carotovora) is probably the principal cause and the most serious in terms of crop losses. Fungal rots are also important. Infection by the late blight pathogen Phytophthora infestans is particularly significant, not just because of the damage it causes per se, but because it also appears to provide potential sites for secondary infection by E. carotovora.

E. carotovora is strongly pectolytic and, under favourable conditions, can rapidly turn an infected

\footnotetext{
* To whom correspondence should be addressed.
}

Accepted 25 January 1999. tuber into soft, wet, rotten tissue, which carries inoculum to healthy tubers and spreads the infection rapidly throughout a store (Bradbury, 1986). Early detection of the disease is vital if it is to be controlled and this could be achieved using vapour sensors that detect volatile organic compounds (VOCs) produced by infection.

Previous studies of potato tubers infected by E. carotovora have identified a range of VOCs evolved during the progression of the disease (Varns \& Glynn, 1979; Waterer \& Pritchard, 1984; Maga, 1994) which might be useful indicators of the onset of infection. Many low molecular weight volatiles, especially alcohols, were evolved during infection (Waterer \& Pritchard, 1984); for example, ethanol, methanol and butan-1-ol were found to increase rapidly as infection progressed (Varns \& Glynn, 1979). However, these volatiles tend 
not to be disease specific and are also evolved when no infecting organisms are present (Maga, 1994).

Knowledge of the volatiles produced from infected and healthy potato tubers is critical in the development of sensor systems capable of detecting the onset of disease in storage.

Gas and vapour detectors are generally nonspecific and can respond to a range of odours (Cowell et al., 1994). Array-based systems or 'artifical noses' (Craven etal., 1996) have been developed to combat this nonspecificity. Essentially, each sensor in an array produces an output in response to its gaseous environment. Measurement of the output from each sensor in the array on exposure to an odour results in a pattern unique to that odour (Brezmes et al., 1997). Patterns are normally interpreted using neural network or pattern recognition algorithms (Getine et al., 1997). Knowledge of the components that comprise an odour is essential in rationalizing the array design and choice of sensors to produce maximum sensitivity and minimum redundancy. This enables the construction of task-specific 'electronic noses' rather than more general arrays that are capable of broad odour classification tasks (Amrani et al., 1997).

Identification of the volatiles generated by potato tubers infected by a variety of micro-organisms will enable the development of a sensor system, based upon the volatiles detected, for the early detection of disease in stored potatoes.

In this study, the typical storage conditions in which soft rots are known to cause the greatest problems were emulated, and the volatiles released were identified in relation to the progress of infection from initial inoculation to expression of characteristic soft-rot symptoms. Preliminary experiments used sensors to detect E. carotovora infections of potato tubers stored at $25^{\circ} \mathrm{C}$ (de Lacy Costello et al., 1996).

\section{Materials and methods}

\section{Micro-organisms}

Erwinia carotovora ssp. carotovora isolate 312 was obtained from the National Collection of Plant Pathogenic
Bacteria (Central Science Laboratory, York YO4 1LZ). Micro-organisms were isolated from uninfected and $E$. carotovora-infected potato tubers by excising small pieces of tuber or soft-rotted tissue, respectively, and plating onto potato dextrose agar (PDA: Oxoid Ltd, Basingstoke, RG24 8PW). Bacterial isolates were purified and identified initially using the Schaad identification scheme (Schaad, 1988). Twenty-nine isolates were subjected to further identification by fatty acid profiling (Central Science Laboratory, York, YO4 1LZ). Isolates identified as B. polymyxa and Arthrobacter sp. were selected for further work.

E. carotovora was grown on PDA, B. polymyxa and Arthrobacter sp. on asparagine agar (dextrose $40.0 \mathrm{~g}$, asparagine $2.0 \mathrm{~g}$, potassium dihydrogen phosphate $0.5 \mathrm{~g}$, magnesium sulphate heptahydrate $0.25 \mathrm{~g}$, thiamine dichloride $0.005 \mathrm{~g}$, agar $15 \mathrm{~g}$, in $1 \mathrm{~L}$ distilled water; Johnston \& Booth, 1983), all at $19^{\circ} \mathrm{C}$.

Bacterial cell suspensions were prepared by adding $10 \mathrm{~mL}$ of sterile distilled water to 4-day-old cultures, gently shaking to produce a dense suspension, then decanting into sterile universal bottles.

\section{Controlled environment apparatus}

A controlled environment apparatus (Fig. 1) (Harrison \& Lowe, 1989) was used to simulate the temperature and humidity found in potato stores as closely as possible. It consisted of two controlled temperature water baths, one containing the sample jars with potatoes and the other containing the humidifying vessels. Blended air was passed from a gas cylinder (MG Gas Products, Reigate, RH29QE) into the humidifying vessels. The humidity of the resultant stream of gas was controlled by the temperature of the first water bath containing the humidifying vessels. The humidified air, at $95 \%$ relative humidity, then flowed into the sample jars in the second bath, which was maintained at $10^{\circ} \mathrm{C}$.

\section{Inoculation of potato tubers}

Tubers of Solanum tuberosum cv. Maris Piper were obtained from Sutton Bridge Experimental Unit (Sutton
Figure 1 Schematic diagram of controlled environment apparatus

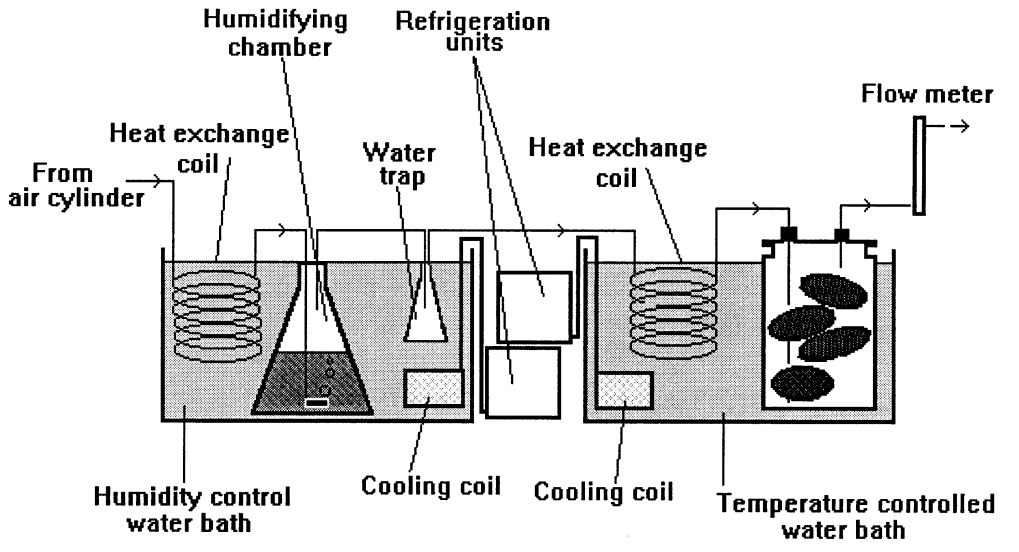


Bridge, Spalding, PE12 9YB). The tubers were washed in water to remove soil, then swabbed with $90 \%$ ethanol and dried in a laminar flow hood. Each tuber had a grid, consisting of two sets of four parallel lines orthogonal to each other and approximately $3 \mathrm{~cm}$ long by $1 \mathrm{~cm}$ deep, cut into the surface (skin) with a sterile scalpel before inoculation with either bacterial suspension $(1 \mathrm{~mL})$, or sterile distilled water for the control.

Inoculated tubers (approximately $0.9 \mathrm{~kg}$ per treatment) were placed in a sterile Quickfit jar (2L) with a multiport lid. One port had a length of silicon tubing threaded through a thermometer adapter, which carried blended air to the bottom of the jar. A second port had a Quickfit tubing adapter connected to silicon tubing to allow air to leave the jar.

The jars were incubated for $12 \mathrm{~h}$ at $25^{\circ} \mathrm{C}$, in the dark, before placing into the waterbath at $10^{\circ} \mathrm{C}$ and connecting to the humidified air supply, which was maintained at $50 \mathrm{~mL} \mathrm{~min}^{-1}$ per jar throughout the experiment. Such an air supply is typical of potato stores with forced ventilation (S. McDonald, Scottish Crop Research Institute, personal communication).

\section{Adsorbent system for sampling volatiles}

The adsorbent system consisted of lengths of deactivated glass-lined tubing $(78 \mathrm{~mm} \times 4 \mathrm{~mm}$ internal diameter $)$ packed with a sandwich of Tenax TA $(10 \mathrm{mg})$ (Jones Chromatography, Hengoed, CF8 8AU), Tenax GR (20 mg, 35/60 mesh) (Jones Chromatography) and Carbosieve III (20 mg, 60/80 mesh) (Supelco UK, Poole, BH12 4QV), contained by silanized glass wool plugs. The adsorbent tubes were conditioned at $250^{\circ} \mathrm{C}$ under a flow of nitrogen $\left(100 \mathrm{~mL} \mathrm{~min}^{-1}\right)$ for $4 \mathrm{~h}$ prior to use. When not in use, the ends of the adsorbent tubes were sealed using Swagelok fittings and stored in a desiccated environment.

\section{Volatile sampling and analysis}

Volatiles were sampled after a period of four weeks. The sample was collected by passing air through the chamber containing the tubers for two hours, using the adsorbent system described. The adsorbent tubes were connected to the outlet of the sample jars via silicon rubber tubing with the Tenax TA end closest to the outlet. Volatiles were collected from each of the jars in turn at a constant flow rate of $50 \mathrm{~mL} \mathrm{~min}^{-1}$ and at $80 \%$ relative humidity. After collection, the adsorbent tubes were analysed using GC-MS as soon as possible. Where the analyses were not possible immediately, the tubes were capped and stored at $-80^{\circ} \mathrm{C}$. Volatiles from the control tubers (inoculated with sterile distilled water) were collected and analysed each time for comparison.

A Hewlett-Packard HP5890 series II GC coupled to a HP5971 Mass Selective Detector was used for vapour analysis. VOC fractionation was achieved using a Supelco SPB-1 Sulfur, fused silica capillary column (30 m, 0.32 $\mathrm{mm}$ i.d., $4 \mathrm{~mm}$ film thickness).
An improvised thermal desorption method was used to transfer the sample onto the GC column (P. R. H. Jones, UWE, Bristol, personal communication). A small loop $(\approx 5 \mathrm{~cm}$ length) of the capillary column close to the injection end was placed in a beaker containing liquid nitrogen. The oven was held at ambient temperature and the injection port at $50^{\circ} \mathrm{C}$. The glass liner of the injector port was removed and the adsorbent tube put in its place. The port temperature was then raised to $200^{\circ} \mathrm{C}$ as quickly as possible, to flash desorb the vapour onto the capillary column. After $10 \mathrm{~min}$, the liquid nitrogen trap was removed. The oven was turned on to $40^{\circ} \mathrm{C}$ and held at $40^{\circ} \mathrm{C}$ for $150 \mathrm{~s}$ to allow air and water to pass through the system without damaging the mass selective detector (MSD) filament. The oven temperature was then programmed to rise from $40^{\circ} \mathrm{C}$ to $200^{\circ} \mathrm{C}$ at $4^{\circ} \mathrm{C} \mathrm{min}^{-1}$ with a hold time of $5 \mathrm{~min}$. The MSD was set up to record a scan range of 10-300 atomic mass units (amu).

Spectral analysis was carried out using proprietary Hewlett Packard software (G1034C, V 01.05) running the NBS75K library. The spectrum obtained was matched as the peak average with the baseline measured by a baseline drop method (where baseline drop was not measured, the integrator took a tangent as the baseline). The integrator was used with a minimum peak area of $0 \cdot 1 \%$ and a maximum of 250 peaks per spectrum. Spectra were matched with and without baseline subtraction. Poorly matched peaks were evaluated manually where possible.

\section{Total volatile nitrogen determination}

A total volatile nitrogen (TVN) analysis was performed on E. carotovora-infected and uninfected tubers that had been incubated for 7,14 and 21 days at $20^{\circ} \mathrm{C}$ to obtain a quantitative measure of the amines released (Sagastizabal, 1996).

A sample of potato tuber $(20 \mathrm{~g})$ was homogenized with distilled water $(200 \mathrm{~mL})$ using a food processor for each analysis. The mixture was then transferred to a round-bottomed flask $(1 \mathrm{~L})$ containing distilled water

Table 1 Identification, by fatty acid profiling, of bacterial isolates from tubers infected by Erwinia carotovora and from uninfected tubers

\begin{tabular}{lll}
\hline \multirow{2}{*}{$\begin{array}{ll}\text { Identity by } \\
\text { fatty acid profiling }\end{array}$} & \multicolumn{2}{l}{ Number of isolates } \\
\cline { 2 - 3 } & Infected tubers & Uninfected tubers \\
\hline Erwinia carotovora & 5 & 0 \\
Arthrobacter sp. & 3 & 1 \\
Bacillus polymyxa & 3 & 4 \\
B. pumilus & 0 & 4 \\
B. cereus & 0 & 3 \\
B. megaterium & 0 & 3 \\
Bacillus sp. & 0 & 1 \\
Agrobacterium sp. & 0 & 1 \\
Cytophagus-Flavobacterium & 0 & 1 \\
complex & & \\
\hline
\end{tabular}


Table 2 Volatile profiles of potato ${ }^{a}$ tubers inoculated with E. carotovora, B. polymyxa, Arthrobacter sp. or sterile distilled water

\begin{tabular}{|c|c|c|c|c|c|}
\hline $\mathrm{RT}^{\mathrm{b}}$ & Volatile & E. carotovora & B. polymyxa & Arthrobacter sp. & SDW \\
\hline $12 \cdot 75$ & Acetone & + & + & + & \\
\hline $13 \cdot 01$ & 2-Propenal & + & & & \\
\hline $13 \cdot 11$ & Acetone & + & & & + \\
\hline $14 \cdot 61$ & 2-Methyl-propanal & + & & & + \\
\hline $15 \cdot 16$ & 2-Methyl-pentane & & + & + & + \\
\hline $15 \cdot 67$ & 3-Methyl-pentane & & & & + \\
\hline $15 \cdot 62$ & 2-Butanone & + & & & + \\
\hline $15 \cdot 71$ & Acetic acid & + & + & + & + \\
\hline $16 \cdot 06$ & 1-Hexene & + & & & \\
\hline $16 \cdot 21$ & Hexane & & + & + & + \\
\hline $18 \cdot 22$ & 1-Butanol & + & & & + \\
\hline $18 \cdot 56$ & But-1-ene & & + & + & \\
\hline $18 \cdot 67$ & Cyclohexane & & + & + & + \\
\hline $18 \cdot 71$ & 2-methyl-1-pentene & & + & + & + \\
\hline $18 \cdot 8$ & (E)-2-Butene & & & & + \\
\hline $18 \cdot 94$ & 2-Methylhexane & + & + & + & + \\
\hline 18.99 & 2-Pentanone & + & & & + \\
\hline $19 \cdot 16$ & 2,3-Dimethyl-pentane & & & & + \\
\hline $19 \cdot 31$ & 3-Methyl-hexane & & + & + & + \\
\hline $19 \cdot 35$ & 2,4-Dimethyl-1-heptene & & & & + \\
\hline $19 \cdot 63$ & 2,3-Dihydrofuran & & & + & \\
\hline $19 \cdot 69$ & 1,2-Dimethyl-cis-cyclopentane & & & + & + \\
\hline $19 \cdot 74$ & (E)-2-Butenal & & & & + \\
\hline $20 \cdot 46$ & Heptane & + & + & + & + \\
\hline $21 \cdot 32$ & Dimethyldisulfide & + & & & \\
\hline $21 \cdot 40$ & Methyl-cyclohexane & + & + & + & + \\
\hline $22 \cdot 18$ & N,N-Dimethyl-formamide & & + & & \\
\hline 23.05 & Toluene & + & + & + & + \\
\hline 23.99 & Hexanal & + & + & & + \\
\hline $25 \cdot 05$ & Octane & + & & + & + \\
\hline $25 \cdot 61$ & Octene & + & & & \\
\hline $26 \cdot 47$ & 2-Methyl-octane & + & & & \\
\hline $27 \cdot 47$ & Ethylbenzene & + & & & + \\
\hline $27 \cdot 87$ & Xylene & + & + & + & + \\
\hline $28 \cdot 14$ & 3,4-Dihydro-2H-pyran & & & & + \\
\hline $28 \cdot 42$ & 3-Methyl-octane & + & & & \\
\hline $28 \cdot 74$ & 1,2,3-Trimethyl-cyclohexane & + & & & \\
\hline $28 \cdot 82$ & 1,2-Dimethyl-benzene & + & & & + \\
\hline $29 \cdot 12$ & 1-Methyl-2-propyl-cyclo-pentane & + & & & \\
\hline $29 \cdot 15$ & 1-Heptene & + & & & \\
\hline $29 \cdot 37$ & 1-Ethyl-4-methyl-cyclohexane & + & & & \\
\hline $29 \cdot 65$ & Nonane & + & & & + \\
\hline $30 \cdot 44$ & 2,4-Dimethyl-hexane & + & & & + \\
\hline $31 \cdot 16$ & Propyl-cyclohexane & + & & & + \\
\hline 31.94 & 1-Ethyl-2-methyl-benzene & + & & & + \\
\hline $31 \cdot 97$ & Phenol & + & & & + \\
\hline $32 \cdot 59$ & 2-Methyl-nonane & + & & & + \\
\hline $32 \cdot 86$ & 3-Methyl-nonane & + & & & + \\
\hline $33 \cdot 29$ & Octanal & + & & & \\
\hline $33 \cdot 40$ & Trimethyl benzene & + & & & + \\
\hline $33 \cdot 56$ & 1-Ethyl-3-metyl-benzene & & + & + & + \\
\hline $33 \cdot 75$ & 2,2,3,4-Tetramethyl-pentane & + & & & \\
\hline $33 \cdot 83$ & 1,2-Undecadiene & + & & & \\
\hline $34 \cdot 08$ & Decane & + & & & + \\
\hline $35 \cdot 03$ & 4-Methyl-decane & + & & & + \\
\hline $35 \cdot 30$ & Limonene & + & & & + \\
\hline $35 \cdot 35$ & 1,3-Pentadiene & & & & + \\
\hline $35 \cdot 53$ & (2-Methyl-propyl)-cyclohexane & + & & & + \\
\hline $35 \cdot 85$ & 1-Methyl-3-propyl-benzene & & & & + \\
\hline $36 \cdot 07$ & 3-Methyl-bicyclo-[3.2.1]-oct-2-ene & + & & & \\
\hline $36 \cdot 15$ & 2-Methyl-decane & & & & + \\
\hline
\end{tabular}


Table 2 (continued)

\begin{tabular}{|c|c|c|c|c|c|}
\hline $36 \cdot 42$ & 3-Methyl-decane & + & & & + \\
\hline $36 \cdot 55$ & 5,6-Dimethyl-decane & + & & & \\
\hline $37 \cdot 26$ & 1-Methyl-4-(1-methyl-ethyl-benzene & + & & & + \\
\hline $37 \cdot 65$ & Nonanol & + & & + & \\
\hline $37 \cdot 77$ & 3-Methyl-1-heptene & + & & & \\
\hline $40 \cdot 16$ & 2,9-Dimethyl-decane & & & & + \\
\hline $41 \cdot 40$ & Napthalene & + & & & \\
\hline $41 \cdot 71$ & Decanal & + & + & + & + \\
\hline $41 \cdot 88$ & 2-Phenoxy-ethanol & + & + & + & + \\
\hline $42 \cdot 21$ & Dodecane & & & & + \\
\hline $43 \cdot 97$ & 1-Pentadecene & & + & & \\
\hline $45 \cdot 74$ & Long chain aliphatic (Heptadecane?) & + & & & \\
\hline $46 \cdot 16$ & Butanoic acid & + & & & \\
\hline $46 \cdot 33$ & $1(3 \mathrm{H})$ /sobenzo-furanone & + & & & + \\
\hline $49 \cdot 22$ & Long chain aliphatic & + & & & \\
\hline $49 \cdot 29$ & Hexacosane & + & & + & \\
\hline $51 \cdot 1$ & Phytol & & + & & + \\
\hline $52 \cdot 57$ & 3,4-Dimethyl-1-decene & + & & & + \\
\hline $52 \cdot 63$ & 3-Methylnonane & + & & & + \\
\hline $57 \cdot 35$ & 1-Hexacosanol & + & & & + \\
\hline $57 \cdot 89$ & 1-Eicosanol & & & & + \\
\hline $58 \cdot 35$ & ((Dodecyloxy)methyl)-oxirane & & & & + \\
\hline $58 \cdot 91$ & 3,5,24-Trimethyl-tetracontane & & & & + \\
\hline $58 \cdot 95$ & 1-Chloro-tetradecane & & + & & + \\
\hline
\end{tabular}

a The tubers were incubated at $10^{\circ} \mathrm{C}$ and $95 \%$ relative humidity under a constant $50 \mathrm{~mL} \mathrm{~min}^{-1}$ flow of air for four weeks prior to sampling

${ }^{\mathrm{b}} \mathrm{RT}$ : Retention time of compound in minutes.

$(100 \mathrm{~mL})$. Magnesium oxide $(2 \mathrm{~g}$, S.L.R, Fisons, Loughborough, LE110RG) was then added to the flask with a drop of silicon oil antifoaming agent (Fisons) and several antibumping granules. Boric acid $(0.65 \mathrm{M}$, $50 \mathrm{~mL}, \mathrm{BDH} /$ Merck, Lutterworth, LE174XN) was added to a conical flask with 6 drops of indicator solution prepared by adding methyl red $(0.2 \mathrm{~g})$ and methylene blue $(0.1 \mathrm{~g})$ dissolved in ethanol $(99.75 \mathrm{v} / \mathrm{v}$, $100 \mathrm{~mL}$ ). The solution containing the homogenized potato was then heated using a Bunsen burner so that it boiled after $10 \mathrm{~min}$. It was then distilled for $25 \mathrm{~min}$ at the same rate of heating, ensuring that the receiver tube from the condenser was immersed in the boric acid solution. After distillation, the condenser and delivery tube were rinsed with distilled water and the distillate was collected in the conical flask. Presence of volatile nitrogen compounds, such as amines, would produce a colour change from purple to green. The distillate was then titrated to a clear end point against a standardized solution of sulphuric acid $(0 \cdot 1 \mathrm{~N}, \mathrm{BDH} / \mathrm{Merck})$. The equation used for the calculation of TVN (in mg of nitrogen per $100 \mathrm{~g}$ of tuber) was:

$$
\mathrm{TVN}=(\mathrm{Vs}-\mathrm{Vb}) \times 14 \times(10 / \mathrm{M}) \times(\mathrm{N} / 0 \cdot 1)
$$

where Vs=sample titre, in $\mathrm{mL}$, of standardized acid, $\mathrm{Vb}=$ blank titre, in $\mathrm{mL}$, of standardized acid, $\mathrm{M}=$ mass in grams of potato tissue, and $\mathrm{N}=$ normality of standardized acid.

\section{Modified GC-MS method for detection of volatile amines and other volatiles}

Gaseous amine standards of ammonia, methylamine, ethylamine, dimethylamine, diethylamine and triethylamine $(0.01 \%$ v/v, Aldrich, Gillingham, SP8 4XT) were sampled as headspace $(20 \mathrm{~mL}$, Hamilton gas tight syringe), and injected into the GC-MS to optimize the column parameters.

Solid phase microextraction (SPME) polydimethylsiloxane/divinylbenzene fibres $(65 \mathrm{~mm}$, partially crosslinked, Supelco UK, Poole, BH12 4QH) were conditioned thermally prior to sample exposure by insertion into the GC injector port $\left(270^{\circ} \mathrm{C}, 30 \mathrm{~min}\right)$. The fibre was exposed to the sample headspace and the entrained analytes thermally desorbed in the injector port $\left(270^{\circ} \mathrm{C}, 4 \mathrm{~min}\right)$ under splitless conditions.

Standards of the amines used $(0 \cdot 01 \% \mathrm{v} / \mathrm{v})$ were purged onto the entrapment systems to determine their efficiency, using charcoal-purified air.

SPME passive sampling was conducted above the headspace of potato samples (approx. $5 \mathrm{~g}$ ) sealed in deactivated HP headspace sample vials $(20 \mathrm{~mL})$ for $5 \mathrm{~min}$. Dynamic sampling was used with Chromosorb 103 and Tenax adsorbents, manufactured as before. Samples of potato tuber $(20 \mathrm{~g})$ sealed in deactivated chambers $(20 \mathrm{~mL})$ were purged with blended air $\left(200 \mathrm{~mL} \mathrm{~min}^{-1}\right.$, for $\left.10 \mathrm{~min}\right)$. GC-MS operating conditions were as before except that the detector was turned on earlier to detect amines.

\section{Results}

\section{Micro-organisms}

Fatty acid profiling of the 11 bacterial isolates from E. carotovora-infected potato tubers revealed that five 
were E. carotovora, three were Arthrobacter spp. and three were B. polymyxa (Table 1).

Fifty-six isolates were collected from uninfected tubers. Preliminary identification using the Schaad scheme and visual comparison of morphological characteristics of cultures reduced this number to 18 for fatty acid profiling (Table 1).

\section{Volatile profiles from potato tubers inoculated with bacteria}

\section{E. carotovora}

Fifty-seven volatiles were identified as being associated with E. carotovora-infected potato tubers at four weeks after inoculation (Table 2). Of these, 22 volatiles were identified solely with the infected tubers, whereas 17 were also found with uninfected tubers. The volatile profile contained 25 alkanes, 10 aromatic species, seven alkenes, five aldehydes, three ketones, three alcohols, two acids, one heterocycle and one sulphide.

Uninfected tubers generated 36 different volatiles, of which five were found to be unique. These were 3,4dihydro-2H-pyran, 1-methyl-3-propylbenzene, 2-methyl decane, 2,9-dimethyldecane and 2,9-dimethyldodecane.

B. polymyxa and Arthrobacter sp.

Of the 22 volatiles associated with $B$. polymyxainoculated potato tubers (Table 2), three (N,Ndimethylformamide, 1-pentadecene and 1-hexadecane) were not obtained from uninoculated control tubers. Arthrobacter sp. produced 20 volatiles (Table 2), of which one (2,3-dihydrofuran) was unique to tubers inoculated with this species.

\section{Total volatile nitrogen determination}

Evidence of amine production was obtained from the results of TVN analysis. A colour change from purple to green was observed in the solution containing the indicators on distillation of E. carotovora-infected potato tubers, but there was no colour change on distillation of healthy tubers.

Calculation of TVN showed that no volatile nitrogen was present in fresh tubers but that there was a steady increase in the amount of volatile nitrogen species present in inoculated tubers (Table 3 ).

\section{Further identification of amines and other volatiles}

The presence of amines and sulphides in the headspace of E. carotovora-infected tubers that had been cultured at $20^{\circ} \mathrm{C}$ was determined by the modified GC-MS method. Ammonia, trimethylamine, dimethylsulphide, dimethyldisulphide and dimethyltrisulphide were detected in significant amounts along with acetone, ethanol and butan-1-ol.

\section{Discussion}

B. polymyxa is pectolytic and commonly found in soils, although it is not considered to be an active plant
Table 3 Total volatile nitrogen (TVN, in mg of nitrogen per $100 \mathrm{~g}$ of tuber) analysis for uninfected and $E$. carotovora-infected potato tubers incubated at $20^{\circ} \mathrm{C}$ postinoculation

\begin{tabular}{lrr}
\hline & \multicolumn{2}{c}{ TVN $^{\mathrm{a}}$} \\
\cline { 2 - 3 } & \multicolumn{1}{c}{ Titre 1 } & Titre 2 \\
\hline Uninfected potato tuber & 0.0 & 0.0 \\
Infected tuber: 7 days & 35.0 & 40.6 \\
Infected tuber: 14 days & $77 \cdot 7$ & 91.7 \\
Infected tuber: 21 days & 109.9 & 114.8 \\
\hline
\end{tabular}

${ }^{\text {a }}$ Table contains repeat titrations for each time interval.

pathogen (Bradbury, 1986). It is frequently associated with plants and can cause rots, although normally this is only observed at high temperatures and/or where there is a lack of oxygen. Other Bacillus spp., such as $B$. megaterium and B. cereus, have been isolated previously from potato tubers, but did not cause obvious symptoms (Hollis, 1951).

It is interesting that both $B$. polymyxa and the Arthrobacter sp. were also isolated from internal tissues of surface sterilized tubers that appeared healthy. These bacteria, together with the other isolates listed in Table 1, are therefore likely to be endophytes (Gunson \& Spencer-Phillips, 1994) that may contribute to the profile of volatiles emitted following E. carotovora infection. For this reason GC-MS analysis was used to analyse volatiles from potato tubers inoculated with E. carotovora, B. polymyxa and the Arthrobacter sp.

It should be noted that the GC-MS method used did not detect some volatiles, such as methanol, ethanol and acetaldehyde, which elute before the water peak has passed through the system. Preliminary work and that of other workers showed ethanol, methanol and acetaldehyde to be present with both infected and uninfected potato tubers (Waterer \& Pritchard, 1984). For this reason, they were not considered to be significant as potential marker volatiles for a soft-rot detection system, even though ethanol was previously identified as one of the most significant vapours when E. carotovora infection occurs. Concentrations were shown to rise by as much as 2000 times with infection (Waterer \& Pritchard, 1984), whilst other alcohols such as propan1-ol remain at relatively constant levels. Other volatiles are less well documented.

The concentration of VOCs evolved from tubers infected by E. carotovora, B. polymyxa and Arthrobacter sp. was very low at $10^{\circ} \mathrm{C}$, in contrast to higher temperatures, necessitating preconcentration of the samples taken. This methodology enabled sufficient VOCs to be collected for analysis. A qualitative study was aimed at ascertaining whether marker volatiles could be identified for the three infecting species. In parallel studies at room temperature, E. carotovorainfected tubers rapidly softened and became macerated. Progress of disease was far slower at $10^{\circ} \mathrm{C}$ resulting in only small isolated areas of rot after 4 weeks incubation. Relatively few volatiles were identified after tubers were 
inoculated with B. polymyxa and Arthrobacter sp. No evidence of infection or damage was visible on the tubers after four weeks, suggesting that the bacteria were not pathogenic under the conditions employed in this study.

No single compound could be used as a marker for a specific bacterial infection of tubers but it appears that an overall increase in volatiles, as described by other workers (Waterer \& Pritchard, 1984), could suffice to indicate the presence of E. carotovora in a stored crop of potatoes and, qualitatively, the balance of volatile components, coupled with the significant increase in total volatile organics, should permit differentiation between the presence or absence of disease in stores. In a parallel study, infections by Fusarium coeruleum and $P$. infestans were observed to progress far more slowly than that by E. carotovora, and did not appear to generate volatiles at the same rate of production (R. Wheatley etal., Scottish Crop Research Institute, personal communication).

The presence of volatile amines in the headspace above rotting potatoes has not been previously reported, although it would seem likely that the micro-organisms would decarboxylate amino acids to form amines. Most of these amines would remain within the tuber as protonated salts because of the relatively low $\mathrm{pH}$.

Tubers inoculated with E. carotovora and incubated at $20^{\circ} \mathrm{C}$ for one week produced volatile amines, while the control tubers produced no volatile amines, or negligible amounts. Ammonia, trimethylamine, dimethylsulphide, dimethyldisulphide and dimethyltrisulphide were detected in significant amounts by a modified GC-MS method. Some potato stores are still maintained at ambient temperatures and therefore the detection of these volatile amines and sulphides could give valuable information about the onset of soft rot in such stores.

In an early warning system to detect the onset of E. carotovora infection, sensors responsive to a broad range of volatiles, such as amines, sulphides, alcohols, hydrocarbons and aldehydes, are required. The array of sensors may be capable of detecting the significant increase in volatiles as a primary indicator of disease and, when coupled with pattern recognition software, could identify the causative agent.

\section{Acknowledgements}

The authors thank: the British Potato Council for funding this project; SCRI, Dundee for collaboration on the volatile collection aspects and the loan of the humidity and temperature control apparatus; Adrian Bridden of Sutton Bridge Experimental Unit for supplying the potato tubers; Peter Jones for development of the GC-MS method; Alan Millett for his assistance with the GC-MS.

\section{References}

Amrani MEH, Dowdeswell RM, Payne PA, Persaud KC, 1997. An intelligent gas sensing system. Sensors and Actuators B-Chemical 44, 512-6.

Bradbury JF, 1986. Guide to Plant Pathogenic Bacteria. Wallingford, UK: CAB International.

Brezmes J, Ferreras B, Llobet E, Vilanova X, Correig X, 1997. Neural network based electronic nose for the classification of aromatic species. Analytica Chimica Acta 348, 503-9.

Cowell DC, Ewen RJE, Flynn CE, Goldie B, Hart JP, Hawkins SJ, Hitch TJAR, Honeybourne CL, McCalley DV, Ratcliffe NM, 1994. Sensors for citrus fruit quality. Life Chemistry Reports 11, 333.

Craven MA, Gardner JW, Bartlett PN, 1996. Electronic noses: development and future prospects. Trends in Analytical Chemistry 15, 486-93.

Getine J, Horrillo MC, Gutierrez J, Ares L, Robla JI, Garcia C, Sayngo I, 1997. Analysis of VOCs with a tin dioxide sensor array. Sensors and Actuators B-Chemical $43,200-5$.

Gunson HE, Spencer-Phillips PTN, 1994. Latent bacterial infections: epiphytes and endophytes as contaminants of micropropagated plants. In: Lumsden PJ, Nicholas JR, Davies WJ, eds, Physiology, Growth and Development of Plants in Culture. Netherlands: Kluwer Academic Publishers, 379-96.

Harrison JG, Lowe R, 1989. Effects of humidity and air speed on sporulation of Phytophthora infestans on potato leaves. Plant Pathology 38, 585-91.

Hollis JP, 1951. Bacteria in healthy potato tissue. Phytopathology 41, 350-66.

Johnston A, Booth C, 1983. Mycological media and methods. In: Plant Pathologists Pocketbook. Wallingord, UK: CAB International, 393-415.

de Lacy Costello BPJ, Ewen RJ, Ratcliffe NM, 1996. Approaches to a sensor system for the early detection of soft rot in stored potato tubers. In: Marshall G, Parry D, eds, BCPC Symposium Proceedings No. 65: Diagnostics in Crop Production. Nottingham, UK: Major Print Ltd. 383-90.

Maga JA, 1994. Potato flavor. Food Review International 10, $1-48$.

Sagastizabal A, 1996. Colorimetric Sensors for Vapour Detection. Bristol, UK: University of the West of England, MPhil Thesis.

Schaad NW, 1988. Initial identification of common genera. In: Schaad NW, ed. Laboratory Guide for Identification of Plant Pathogenic Bacteria. Minnesota, USA: American Phytopathological Society, 1-15.

Varns JL, Glynn MT, 1979. Detection of disease in stored potatoes by volatile monitoring. American Potato Journal 56, 185-97.

Waterer DR, Pritchard MK, 1984. Monitoring of volatiles: a technique for detection of soft rot (Erwinia carotovora) in potato tubers. Canadian Journal of Plant Pathology 6, 165 . 